\title{
Food, mood and health: a neurobiologic outlook
}

\section{Prasad}

\author{
Correspondence \\ C. Prasad \\ Department of Medicine \\ Louisiana State University \\ Medical Center \\ 1542 Tulane Ave \\ New O rleans, LA 70112 \\ USA \\ Fax: + 1-504-568-4159 \\ E-mail: cprasa@ Isumc.edu
}

Presented at the XIII Annual Meeting of the Federação de Sociedades de Biologia Experimental, Caxambu, MG, Brasil, August 26-29, 1998.

Received September 1, 1998 Accepted O ctober 2, 1988
Section of Endocrinology \& M etabolism, Department of M edicine,

LSU Medical Center, New O rleans, LA, USA

\section{Abstract}

Hippocrates was the first to suggest the healing power of food; however, it was not until the medieval ages that food was considered a tool to modify temperament and mood, although scientific methods as we know them today were not in use at the time. Modern scientific methods in neuroscience began to emerge much later, leading investigators to examine the role of diet in health, including mental wellbeing, with greater precision. This review shows how short- and longterm forced dietary interventions bring about changes in brain structure, chemistry, and physiology, leading to altered animal behavior. Examples will be presented to show how diets alter brain chemistry, behavior, and the action of neuroactive drugs. Most humans and most animal species examined in a controlled setting exhibit a fairly reproducible pattern of what and how they eat. Recent data suggest that these patterns may be under the neurochemical and hormonal control of the organisms themselves. Other data show that in many instances food may be used unconsciously to regulate mood by seemingly normal subjects as well as those undergoing drug withdrawal or experiencing seasonal affective disorders and obesity-related social withdrawal. We will discuss specific examples that illustrate that manipulation of dietary preference is actually an attempt to correct neurochemical make-up.

\section{Introduction}

Modern medical science has made imposing progress in understanding the role of dietary nutrients - both macro- and micronutrients - in the maintenance of normal health and in the prevention of diseases like scurvy, pellagra, marasmus, Kwashiorkor, and many others. In the last few decades, an impressive volume of research has been performed and scholarly articles have been written on the role of nutrition in brain development and mental health (1). I doubt that many scientists today would disagree that nutrition plays a critical role in prenatal and early postnatal development of the brain at all levels, including structural, chemical, pharmacologic, and functional. This review bypasses discussions related to the role of nutrition in the developmental maturation of the brain and focuses instead on the role nutrition may play in the restructuring and functional modulation of the adult brain.

When we speak of nutrition and health, we generally think of nutrition in relation to the prevention or even treatment of cancer or of obesity and related disorders. This is merely a reflection of the fact that not only have we 
learned a great deal about the role of diet in cancer and obesity, but that such discoveries make for popular reading and that the news media are very interested in them. Most of us, however, rarely relate diet and nutrition to mental health. Only recently have we realized the potential of certain dietary nutrients and supplements (macronutrients, antioxidant vitamins, and minerals) in the control of bodily functions, including mental performance (2). This is supported by the fact that in the Western world alone, contemporary interest in maintaining and enhancing both body and mind through diet and dietary supplementation has generated a multibillion dollar industry.

However, the use of diet to enhance mental function is not a recent phenomenon. The concept that food can help or hinder health was known and used by physician priests at the time of Aesculapius and centuries before (3). The use of nutrition in patient care also was a common practice at the time of Hippocrates. This is evident from one version of the physician's oath by Hippocrates, part of which reads as follows: "I will apply dietetic measures for the benefit of the sick according to my ability and judgment; I will keep them from harm and injustice". Medical nutrition was at its pinnacle during the Middle Ages, when it was common to prescribe diet therapy as the sole treatment or as an adjuvant to standard medication and surgery for a disease. Maimonides or Moses ben Maimon (1135-1204), the philosopher, rabbi, and physician, advocated that any illness curable by diet alone should not otherwise be treated (3). In the medieval holistic view of nature, mood was thought to be modulated by foods. The assertive relationship between food and mood is documented in many medical culinary textbooks of the period; unfortunately, most are written in medieval Latin, Hebrew, Arabic, and early English dialects, with few English translations. For medieval man, every food item was important since it was associated with good or bad effects that might be immediate or delayed. Such effects were related to the food itself rather than to its caloric density and composition. For example, some foods were considered erotic stimulants (eggs, peacock, beef, pomegranates, apples); others were used as mood enhancers (quince, dates, elderberries) or tranquilizers (lettuce, purslane, chicory).

Twentieth century literature on the impact of diet and nutrition on mental health and behavior is laced with controversial reports, particularly when they involve investigations on human subjects. The reasons for such controversies are many. Often, overenthusiastic scientists and news-starved media are too eager to jump to far-reaching conclusions based on often soft or preliminary data. Many times, anecdotal data creep into scientific literature and with time come to be viewed as truth. Additionally, it is often expensive and difficult to run well-designed long-term human nutritional trials, making it difficult to support or refute anecdotal observations circulating in the literature. I must mention, however, that there are some excellent short-term human trials that have examined the role of diet in human behavior. I will discuss some of these studies later in this review. On the other hand, a wealth of information emerging from animal studies unequivocally suggests a role for diet, nutrition and nutritional supplements in modulating not only brain chemistry and behavior but possibly the structural elements of the brain.

\section{Dietary influences on brain chemistry}

Neurotransmitters and neuromodulators are basic units of chemical communication within the nervous system. These include a variety of phenethylamines and their derivatives (dopamine, norepinephrine, epinephrine, tyramine, octopamine, and tetrahydroisoquinolines), indoleamines (serotonin, melatonin, and tryptamine), cholinergics (acetylcholine and choline), amino acids and 
their derivatives (glutamate, aspartate, glycine, taurine, histamine and gamma-amino butyric acid), nucleosides (adenosine and inosine), hormones (prostaglandins, corticosteroids, estrogen, testosterone, thyroid hormone and many others), and peptides (enkephalin, endorphin, substance P, cholecystokinin, somatostatin, cyclo (His-Pro), thyrotropin releasing hormone and many others). Most of these are synthesized de novo using precursors provided by the food that we eat and thus are under direct influence of the diet. As an example, I will discuss the role of dietary protein and carbohydrate in the synthesis of serotonin, a neurotransmitter ubiquitous throughout the nervous system.

A carbohydrate-rich/protein-poor diet increases and a protein-rich diet decreases brain serotonin synthesis. The following is an explanation of the biochemical basis for the dietary control of serotonin synthesis. The synthesis of serotonin in the brain is limited by the availability of tryptophan. The large neutral amino acids (LNAA), tryptophan, valine, leucine, isoleucine, methionine, phenylalanine, and tyrosine, share the same transport carrier across the blood-brain barrier (4). At physiologic blood amino acid concentrations, there is competition for available carrier sites. Therefore, the transport of blood tryptophan into the brain is proportional to the ratio of its concentration to that of the sum total of other LNAA (4). Consumption of a protein-rich meal raises the blood level of many amino acids. Tryptophan is one of the least common amino acids in dietary protein. Therefore, a protein-rich meal contributes proportionately more competing LNAAs than tryptophan, resulting in reduced entry of tryptophan into the brain and reduced serotonin synthesis.

Conversely, a carbohydrate-rich meal can also alter blood amino acid levels (5). This effect is mediated by the action of insulin, which promotes the uptake of most amino acids by muscle, which accounts for $>45 \%$ of lean body weight. Muscle metabolizes branch-chain amino acids, thereby lowering their concentration in the blood. Plasma tryptophan levels are unaltered by carbohydrate consumption, and insulin does not promote the net uptake of tryptophan into muscle because this amino acid is largely bound to low-affinity, high-capacity sites on albumin. Normally, 75 to $85 \%$ of plasma tryptophan is bound to albumin. When insulin is secreted, the plasma levels of nonesterified fatty acids (NEFAs) fall because insulin promotes uptake of NEFAs by adipocytes. NEFAs also are adsorbed on circulating albumin, thereby increasing the number of sites available on albumin for binding tryptophan. This rise in bound tryptophan compensates for the slight fall in plasma free tryptophan caused by insulin-mediated uptake of amino acids by muscle. The total amount of tryptophan in plasma (bound plus free) determines the rate of transport of tryptophan into the brain because the affinity of the transport system for tryptophan is much greater than the affinity of albumin for tryptophan. Thus, ingestion of a high-carbohydrate/low-protein meal facilitates entry of tryptophan into the brain (6).

Once in the brain, tryptophan undergoes a series of enzymatic reactions, resulting in the synthesis of the neurotransmitter serotonin. The first (and the rate-limiting) step in the conversion of tryptophan to serotonin is hydroxylation of tryptophan by the enzyme tryptophan hydroxylase, a low-affinity $\left(\mathrm{K}_{\mathrm{m}}\right.$ $=0.4 \mathrm{mM}$ ) enzyme that is abundant in the brain. Accordingly, whenever the brain tryptophan level rises, more serotonin is produced (7). Rats fed or injected with tryptophan have higher brain serotonin levels than do controls. Conversely, rats fed a corn diet (tryptophan-poor) have low levels of brain serotonin (8).

\section{Neuroactive substances in food}

Many of the neurotransmitter substances 
discussed above are present in our foods and, therefore, can directly influence brain chemistry. Here I talk about food-borne neurotransmitters/neuromodulators. Long ago, Hippocrates, the father of medicine, said, "Let your food be your medicine, and your medicine be your food". The coming century holds great promise and the opportunities to test the accuracy of this statement. Epidemiologic studies over the last sixty years have clearly linked diet and lifestyle with cancer and cardiovascular diseases (9). In these studies, the disease-modulating activity of food has generally been associated with caloric density or macronutrient composition. For example, a diet high in fat has been associated with an increased risk of breast cancer and atherosclerosis. However, new knowledge, some anecdotal and some scientific, about mental health and foods has just begun to emerge (10); antioxidant vitamins and minerals, for example, are thought to attenuate progression of neurodegenerative diseases and seizure. Such effects of foods are more likely to be associated with the presence of neuroactive substances in foods rather than with their caloric density. This section will provide a very brief overview of the types of neuroactive substances found in food.

\section{Serotonin}

Serotonin is a chemical the brain produces from tryptophan. Where do we get tryptophan? From the protein in our food. Brain serotonin controls many different types of bodily functions, including appetite, body temperature, libido, and mood, to name a few. Some of the foods rich in serotonin and tryptophan include clams, oysters, escargots, octopus, squids, banana, pineapple, plum, nuts, milk, and turkey.

\section{Cyclo(His-Pro)}

Cyclo(His-Pro) or CHP has profound ef- fects on satiety, hunger, and behavior (11). Chemical substances like CHP are common in fermented foods or foods containing hydrolyzed proteins. For example, high levels of CHP are found in nutritional supplements derived from the hydrolysis of casein, a milk protein, and from soy protein. During a search for CHP in food, we found that many protein-derived processed foods contain copious levels of CHP. These included nutritional supplements (e.g., Ensure Plus and Two Cal HN), shrimp, tuna, and a variety of other food products (11). Other foods rich in CHP include milk, yogurt, and buttermilk (11).

\section{Cholecystokinin}

Like CHP, cholecystokinin (CCK) is also found naturally in our brain and gut. Soon after we begin to eat, CCK begins to be released from our gut. When the blood level of CCK rises to a critical level, we feel satiated and stop eating (12). The release of CCK after satiety has been achieved is terminated by the action of trypsin on gut cells $(13,14)$. For that reason there is now substantial interest in developing CCK as a drug for appetite control. Unfortunately, large doses of CCK act on sites in the brain that control anxiety and panic behavior (15). One solution to this problem might be the use of food rich in CCK. Unfortunately, to date we know of no such natural food. This does not mean CCK does not exist in natural foods, only that no one has taken time to screen common foods for this peptide. Meanwhile, there are data to suggest that the use of certain foods to increase blood CCK levels may be possible. For example, many animal and human studies show that a diet containing soy protein, a rich source of trypsin inhibitor, may increase circulating level of CCK. Actually, any food rich in trypsin inhibitors should result in increased CCK secretion and early satiety.

Two other food-derived substances must 
be mentioned here. The first is peptone broth, a great stimulus for CCK secretion. The second is phenylalanine, a natural amino acid that comes from digestion of proteinrich foods such as casein or soy protein. Phenylalanine has been shown to be a potent stimulant of gut CCK release in human and animal studies (16), as well as a powerful inhibitor of food intake in hungry human subjects.

\section{Exorphins}

Exorphins (exo $=$ exogenous or from outside, orphin $=$ morphin, an opium), the opposite of endorphins, are a family of foodderived peptides that act on brain opiate receptors. Dr. Werner Klee of the National Institutes of Health has shown that when pepsin, an enzyme found in stomach, acts on casein (a milk protein), it generates many peptides, some of which interact with opium receptors in the brain; he called these peptides "casomorphins" (17). Today we know of many peptides that come from gluten (a wheat protein), zein (a corn protein) and casein and act as opium antagonists, which, in addition to being appetite suppressants, affect a variety of other central nervous system functions, including mood.

\section{Heterocyclic amines}

These amines comprise a family of bioactive substances in food that are not endogenous to food but are produced during its preparation or processing. Earlier I talked about the high levels of CHP in proteinderived nutritional supplements like Ensure Plus that are produced by a combination of enzymatic hydrolysis of proteins and heat treatment. I also must mention two heterocyclic amines (18) that are products of tryptophan pyrolysis and that are present in meat and fish cooked on an open flame; these were identified as 3-amino-1,4-dimethyl-5Hpyridol[4,3- $b]$ indole (Trp-P-1) and 3-amino-
1-methyl-5H-pyridol[4,3-b] indole (Trp-P$2)$. These compounds are related to $\beta$ carbolines with structures similar to 1-methyl-4-phenyl-1,2,3,6-tetrahydropyridine (MPTP), a man-made agent known to cause Parkinson's disease. Functionally, however, they are quite opposite to MPTP. Systemic administration of Trp-P-1 and Trp-P-2 to mice caused a marked increase in the neurotransmitter dopamine (DA) and a decrease in DA metabolites in the brain, suggesting inhibition of enzyme monoamine oxidase in vivo. These data suggest the possibility of altering DA-dependent behaviors following consumption of foods containing these heterocyclic amines.

\section{Human studies - from anecdote to sound science}

Since long-term controlled clinical studies on the effects of diet on human behavior are logistically difficult to conduct, most published studies are either anecdotal in nature or epidemiologic and plagued with poor design. Epidemiologic studies generally require subjects - or sometimes an acquaintance of the subject - to fill out questionnaires that involve recalling past events, a potential source of error. This is the major reason for inconsistencies in the conclusions of different reports. Despite these problems, a careful meta-analysis of such research often yields a fairly accurate idea of the role diet may play in human behavior. Let's take a specific example: much has been written about the alleged relationship between refined sugars in the diet and hyperactivity in children and criminality in adults. Some of these studies suggest that excessive ingestion of simple sugars (i.e., sucrose and glucose that can be present in granulated sugar, cookies, cereals, chocolates, and sweets) has profound effects on human physiology, behavior, and intellectual functions (19). Other studies have found no effect on blood glucose regulation, mood, bodily symptoms, 
or cognitive function in persons reporting two or more years of heavy consumption of refined sugar (20-22). The truth probably lies somewhere between these extremes. The behavioral sensitivity to sugar and other dietary constituents may vary from individual to individual, and the effects on behavior may be more subtle than many investigators realize or wish to acknowledge.

In contrast, dietary supplements capable of having direct effects on brain neurotransmitter make-up may exert profound effects on human behavior. These include substances that act as neurotransmitter precursors (e.g., tyrosine, tryptophan, choline, and lecithin) or modulators of post-receptor events (e.g., caffeine). The different behavioral effects of diet and dietary supplements on humans involve changes in sleep patterns, perception of pain, and mood, to name a few.

\section{Sleep}

The amino acid composition of a single meal designed to affect brain tryptophan availability has been shown to modulate sleep behavior in newborns (23). Similarly, many studies conducted on adult humans receiving various dosages of tryptophan by different routes of administration $(10-500 \mathrm{mg} / \mathrm{kg}$, orally, to much lower intravenous doses) show that tryptophan increases drowsiness and feelings of fatigue and lethargy (24-27). In healthy female adult humans (28), one week of daily consumption of a low-carbohydrate diet (50 g/day) caused a significant increase in REM sleep latency ( $66 \pm 8$ to 111 $\pm 38, \mathrm{P}<0.05$ ). In contrast, when the relationship between a 5-day self reported dietary history and the response to a sleep questionnaire was analyzed, no link between sleep and diet was found in adults (29). This suggests that it may be necessary to use high levels of a dietary supplement or to institute major dietary changes to see an effect on behavior.

\section{Pain perception}

In a controlled double-blind crossover study, $50 \mathrm{mg} / \mathrm{kg}$ oral tryptophan reduced pain sensitivity to moderate but not to very mild or very painful stimuli (25). In a doubleblind study, patients with chronic maxillofacial pain reported a $50 \%$ reduction in pain after 4 weeks of a high-carbohydrate diet and $3 \mathrm{~g}$ oral tryptophan daily; in contrast, the placebo group reported only a $20 \%$ reduction in pain (30). In another study, tryptophan-treated patients undergoing rhizotomy and cordotomy also reported a reduction in chronic pain (31). In a preliminary study, tryptophan has also been shown to potentiate electrically induced endorphin analgesia (32).

\section{Mood}

The association between food intake or eating patterns and mood is of great interest to scientists and lay persons alike. In addition to an abundance of anecdotal reports in the literature, there is considerable scientific evidence demonstrating that food influences mood and performance. It has been suggested that many patients consume large quantities of carbohydrate-rich food (33-37) to elevate their mood; these include those diagnosed with conditions with a significant depressive component such as seasonal affective disorder (or winter depression), premenstrual stress syndrome, or nicotine withdrawal. Consumption of carbohydrate-rich food may elevate mood in such individuals by raising brain serotonin levels. Dexfenfluramine, an agent known to facilitate brain serotoninergic activity, is also known to elevate mood state in all of the above-mentioned conditions. Incidentally, vitamin $\mathrm{D}_{3}$ has been shown to enhance mood in healthy subjects prone to winter depression (38). It remains to be seen whether vitamin $D_{3}$ acts by raising brain serotonin levels or through some other mechanism. 
The relationship between food and mood in seemingly normal individuals is not a simple one but instead depends on the time of day, the type and macronutrient composition of food, the amount of food consumed, and the age and dietary history of the subject (39). For example, while skipping breakfast impairs cognitive performance (40), a largerthan-normal breakfast improves recall performance but impairs concentration (41). Furthermore, changes in the macronutrient composition of breakfast have differential effects on mood (42). For example, changes in mood have been produced most effectively by raising brain serotonin levels by administering tryptophan or by supplementing a carbohydrate-rich/protein-poor diet with tryptophan (43). I have discussed the theoretical basis for this approach in greater detail earlier.

\section{Dietary influences on animal behavior - a road to human studies}

While there is no doubt that our ultimate goal is to understand how diet and nutrition can affect human mood and health, such knowledge is difficult to come by for reasons discussed earlier. Animal studies designed to study the effect of food on mood, then, are the gateway to future human study. Here, I summarize the results of some of the animal studies conducted over the years in my laboratory on the role of dietary macronutrients in brain structure, chemistry, and behavior in adult animals.

Both undernutrition and overnutrition in preweaning rats result in long-lasting functional changes in the brain. The effects of protein undernutrition on behavior, brain development, and intellectual function are well known $(2,44)$. Unfortunately, there are far fewer studies on the effect of long-term excess consumption of any macronutrient particularly protein - on the brain. Some reported studies on the effect of protein overnutrition on behavior are not rigorous in design and data analysis. For example, it has been reported that adult rats consuming a high-protein diet become more easily frightened and "snappish" (45). A few years ago, we undertook a series of studies to evaluate the effect of long-term (20-36 weeks) consumption of isocaloric high $(50 \%$ of total calories; HP)-, moderate ( $20 \%$ of total calories; MP)-, and low-protein (5\% of total calories; LP) diets on a variety of behavioral measures. These included the adhesive patch test and negative geotaxis commonly used to evaluate sensorimotor function; locomotor activity and stereotypy as measures of ambulatory and searching behavior; the tail-flick test for nociception, and the elevated plusmaze test as a measure of anxiety and aversive behavior. The HP group was more responsive compared with the MP or LP groups in sensorimotor function, negative geotaxis, and spontaneous locomotor activity (46). In addition, the HP group exhibited reduced aversion as measured by the elevated plusmaze test of anxiety and hyperalgesia as shown by tail-flick reaction time (46). These data suggested that long-term consumption of an HP diet may lead to hyperactivity and hyperresponsiveness to the environment, a change that may not always be desirable. In a separate study, we examined whether the HP diet had any effect on learning, memory, and sensory discrimination. The results of these studies showed the following: in the swim cylinder of Porsolt, which tests adaptation to stress, HP rats were significantly less able than was the control group (MP rats) to develop an effective coping strategy (47); during the recording of auditory-evoked responses to deviant tones, short-term auditory memory traces degraded more quickly in the HP rats (47), and finally, in the Morris water maze, diet had no significant effect on acquisition and recall of spatial information (47). These data suggest that a long-term HP diet may precipitate a deficit in short-term but not long-term memory and a diminution in the ability to cope with acute stress. 
A review of the literature indicates that a number of food constituents (e.g., dietary macronutrients and neurotransmitter amino acid precursors) as well as food deprivation may modulate development of tolerance and physical dependence and influence self-administration of several drugs of abuse in animals (48). In an effort to examine further the nature of neuronal changes responsible for perturbation of spontaneous unprovoked motor behavior in animals consuming the HP diet, we examined the sensitivity of HP, MP, and LP mice to a variety of neurotropic agents such as amphetamine, apomorphine, haloperidol, etc. The following is a summary of our studies on amphetamine. Adult ICR mice were put on HP, MP, or LP diets for 35 weeks. At the end of this period, all mice were tested for spontaneous locomotor activity (SLA) and stereotypic behavior (SB) after administration of vehicle or amphetamine $(0.1$ or $1.0 \mathrm{mg} / \mathrm{kg})$. Both SLA and SB, in the absence of amphetamine, increased with increasing levels of protein in the diet (49). Mice on the LP but not the MP or HP diets increased SLA and SB on low-dose $(0.1 \mathrm{mg} / \mathrm{kg})$ amphetamine. Mice on HP but not LP or MP diets, however, failed to respond to high-dose amphetamine $(1 \mathrm{mg} / \mathrm{kg})$. These data suggest that long-term consumption of an HP diet not only may lead to hyperactivity and hyperresponsiveness to the environment but may attenuate neuronal sensitivity to amphetamine and possibly other drugs of abuse. It is generally accepted that amphetamine-induced locomotion is mediated by mesolimbic DAergic neurons, whereas stereotypy is associated with nigrostriatal neurons (49). Furthermore, there is abundant evidence that DA alone is largely responsible for the effect of amphetamine on SLA and SB. Therefore, it seems that a longterm HP diet may modulate multiple DAergic pathways in the brain; it is not clear how the HP diet may affect other neuronal systems. To gain further insight into the effect of dietary protein on the neurochemical make- up of the brain, we examined the distribution of DA, DA-metabolites (dihydroxyphenylacetic acid (DOPAC) and homovanillic acid (HVA)), norepinephrine (NE), serotonin (5HT), and 5-hydroxyindolacetic acid (5HIAA) in the brains of rats consuming LP, MP, and HP diets for 36 weeks. Here I discuss only the data on DA and its metabolites.

In the substantia nigra, the striatum, and the dentate gyrus, DA levels decreased and increased, respectively, with a decrease and increase in dietary protein $(\mathrm{P}<0.05$ compared with the MP diet) (50). The nigrostriatal system is important to a number of behaviors related to sensorimotor integration and response initiation, including extrapyramidal movement, aphagia and adipsia, emesis, and stereotypy (51-55). Our behavioral studies have shown that the HP diet produces hyperactivity. These neurochemical data suggest that an increase in DA in the nigrostriatal system may contribute to behavioral hyperactivity in HP rats. In the mesolimbic system, dietary manipulation had the most marked effect on DA metabolism. There was a diminution in amygdala DOPAC/DA and HVA/DA ratios in the rats on the HP diet, suggesting a decrease in the firing of DAergic neurons in this region. DA transmission in this region is implicated in emotion, sexual behavior, and the reward properties of many drugs of abuse (56-59). Therefore, it is conceivable that reduced sensitivity to SLA and SB after amphetamine administration to HP rats may be related to changes in DA metabolism.

In addition to its neurochemical and behavioral effects, the level of protein in the diet has also been shown to have a profound effect on food intake, body weight, and body composition. For example, White et al. (60) have recently shown that rats given a lowprotein (5\%) diet for only 11 days, compared with those on a $20 \%$-protein diet, increased NPY gene expression in the hypothalamus, resulting in augmented caloric intake. In rats 
on $5 \%$ protein, while their average daily food intake was increased by $20 \%$, their body weight gain was severely attenuated, and body composition analysis revealed increased water retention, decreased body protein, and increased body fat. While these studies underscore the effect of a low-protein diet-mediated increase in NPY gene expression on appetite, other behavioral consequences associated with increased NPY remain to be elucidated.

\section{Concluding remarks}

Proteins, carbohydrates and fats - the major constituents of our diet - serve not only as an energy source but as precursors to a variety of neuroactive substances. The socalled minor constituents of food - minerals and vitamins - are just now being recognized for their many nontraditional functions (e.g., as antioxidants) in health maintenance and promotion. In addition, food is a rich source of many bioactive substances like amino acids, peptides, and others. While some of these bioactive substances (CHP, casomorphins, and a variety of other sub- stances capable of interacting directly with neurotransmitter receptors) can have a direct effect on neuronal functions, others serve as precursors (tryptophan, tyrosine, etc.) or modulators (heterocyclic amines, phenylalanine, etc.) of classical neurotransmitters (DA, norepinephrine, serotonin, acetylcholine, endorphin, etc.). Furthermore, the use of neurotransmitter precursors as dietary supplements in both humans and animals has shown profound effects on neurochemistry and behavior.

Food and dietary supplements, if used properly and wisely, may help us live healthier lives. Although ingestion of minute amounts of any given compound through food may not have any good or bad consequences, a variety of foods in combination may indeed affect mood and health. Some of these substances, such as peptides, are naturally present in food (e.g., CHP in shrimp and tuna), whereas others arise from in vivo digestion of food (e.g., opiate antagonists from casein in milk) or from the use of protein hydrolysates as food (e.g., Ensure from casein and soy protein).

\section{References}

1. Galler J R \& Ross R (1993). Malnutrition and mental development. In: Suskind RM \& Lewinter-Suskind L (Editors), Textbook of Pediatric Nutrition. Raven Press, New York, 173-179.

2. Zeisel SH (1986). Dietary influences on neurotransmission. Advances in Pediatrics, 33: 23-47.

3. Cosman MP (1983). A feast for Aesculapius: Historical diets for asthma and sexual pleasure. Annual Review of Nutrition, 3: 1-33.

4. Pardridge WM (1977). Regulation of amino acid availability to the brain. In: Wurtman RJ \& Wurtman JJ (Editors), Nutrition and the Brain. Raven Press, New York, 141-204.

5. Adibi SA, Morse EL \& Amin PM (1975). Role of insulin and glucose in the induction of hypoaminoacidemia in man: Studies in normal, juvenile diabetic, and insulinoma patients. J ournal of Laboratory and Clinical Medicine, 86: 395-409.

6. Fernstrom JD \& Wurtman RJ (1971). Brain serotonin content: Increase following ingestion of carbohydrate diet. Science, 174: 1023-1025.

7. Fernstrom JD \& Wurtman RJ (1972). Brain serotonin content: Physiological regulation by plasma neutral amino acids. Science, 178: 414-416.

8. Beas-Zarate $C$, del Angel Meza AR, Morales-Villagran A \& Feria Velasco A (1988). Serotonin uptake in the central nervous system of rats fed a com-diet. Comparative Biochemistry and Physiology. C, Comparative Pharmacology and Toxicology, 89: 173-177.

9. Piani A \& Schoenborn CA (1993). Health promotion and disease prevention: United States, 1990. Vital Health Statistics, 10: 185.
10. Anonymous (1997). The neurological role of antioxidants. VERIS Research Summary. Veris Research Information Service, La Grange, IL, 1-6.

11. Prasad C (1989). Neurobiology of cyclo(His-Pro). Annals of the New York Academy of Sciences, 553: 232-251.

12. French SJ, Murray B, Rumsey RDE, Sepple CP \& Read NW (1993). Is cholecystokinin a satiety hormone? Correlations of plasma cholecystokinin with hunger, satiety and gastric emptying in normal volunteers. Appetite, 21: 95-104.

13. Calam J , Bojarski J C \& Springer CJ (1987). Raw soya-bean flour increases cholecystokinin release in man. British J ournal of Nutrition, 58: 175-179.

14. Watanabe SI, Takeuchi $\mathrm{T} \&$ Chey WY (1992). Mediation of trypsin inhibitor-induced pancreatic hypersecretion by secretin and cholecystokinin in rats. Gastro- 
enterology, 102: 621-628.

15. Bourin M, Baker GB \& Bradwejn J (1998). Neurobiology of panic disorder. J ournal of Psychosomatic Research, 44: 163-180.

16. Mathur R \& Manchanda SK (1991). Ontogeny of phenylalanine (endogenous cholecystokinin) induced modulation of food intake in normal and undernourished rats. Progress in Neuro-Psychopharmacology and Biological Psychiatry, 15: 405413.

17. Teschemacher $\mathrm{H}$, Koch $\mathrm{G} \&$ \& Brantl $\mathrm{V}$ (1997). Milk protein-derived opioid receptor ligands. Biopolymers, 43: 99-117.

18. Ichinose H, Ozaki N, Nakahara D, Naoi M, Wakabayashi K, Sugimura T \& Nagatsu T (1988). Effects of heterocyclic amines in food on dopamine metabolism in nigrostriatal dopaminergic neurons. Biochemical Pharmacology, 17: 3289-3295.

19. Yudkin J (1982). Pure, White and Deadly: The Problem of Sugar. Davis Poynter, New York.

20. Horton J R \& Yates AJ (1987). The effects of long-term high and low refined-sugar intake on blood glucose regulation, mood, bodily symptoms and cognitive functioning. Behavior Research and Therapy, 25: 57-66.

21. Breakey J (1997). The role of diet and behavior in childhood. J oumal of Pediatric Child Health, 33: 190-194.

22. Rapoport J L (1982/83). Effects of dietary substances in children. J ournal of Psychiatric Research, 17: 187-191.

23. Yogman MW \& Zeisel SH (1983). Diet and sleep patterns in newborn infants. New England J ournal of Medicine, 309: 11471149.

24. Hartmann E (1983). Effects of 1-tryptophan on sleepiness and sleep. J ournal of Psychiatric Research, 17: 107-113.

25. Lieberman HR, Corkin S, Spring BJ, Growdon J H \& Wurtman RJ (1983). Mood performance and pain sensitivity: Changes induced by food constituents. J ournal of Psychiatric Research, 17: 135145.

26. Leathwood PD \& Pollet P (1983). Diet induced mood changes in normal populations. J ournal of Psychiatric Research, 17: 147-154.

27. Charney DS, Heninger GR, Reinhard J F, Sternberg DE \& Hafstead KM (1982). The effect of IV 1-tryptophan on prolactin, growth hormone, and mood in healthy subjects. Psychopharmacology, 78: 3843.

28. Kwan RM, Thomas S \& Mir MA (1986). Effects of a low carbohydrate isoenergetic diet on sleep behavior and pulmonary functions in healthy female adult humans. J ournal of Nutrition, 116: 2393-2402.

29. Neumann M \& J acobs KW (1992). Relationship between dietary components and aspects of sleep. Perceptual and Motor Skills, 75: 873-874.

30. Seltzer S, Dewart D, Pollack RL \& J ackson E (1982/83). The effects of dietary tryptophan on chronic maxillofacial pain and experimental pain tolerance. J ournal of Psychiatric Research, 17: 181-186.

31. King RB (1980). Pain and tryptophan. J ournal of Neurosurgery, 53: 44-52.

32. Hosobuchi Y, Lamb S \& Baskin D (1980). Tryptophan loading may reverse tolerance to opiate analgesics in humans. A preliminary report. Pain, 9: 161-169.

33. Christensen $L$ (1997). The effect of carbohydrates on affect. Nutrition, 13: 503-514.

34. Neumeister A, Praschak-Rieder N, Hesselmann B, Vitouch $O$, Rauh $M$, Barocka A \& Kasper S (1997). Rapid tryptophan depletion in drug-free depressed patients with seasonal affective disorder. American J ournal of Psychiatry, 154: 1153-1155.

35. Krauchi K, Wirz-J ustice A \& Graw P (1993). High intake of sweets late in the day predicts a rapid and persistent response to light therapy in winter depression. Psychiatry Research, 46: 107-117.

36. Sandyk R (1992). L-tryptophan in neuropsychiatric disorders: a review. International J ournal of Neuroscience, 67: 127144.

37. Wurtman RJ \& Wurtman JJ (1995). Brain serotonin, carbohydrate-craving, obesity and depression. Obesity Research, 3: 477S-480S.

38. Lansdowne AT \& Provost SC (1998). Vitamin D3 enhances mood in healthy subjects during winter. Psychopharmacology, 135: 319-323.

39. Rogers PJ \& Lloyd HM (1994). Nutrition and mental performance. Proceedings of the Nutrition Society, 53: 443-456.

40. Pollitt E, Liebel RL \& Greenfield D (1981). Brief fasting, stress and cognition in children. American J oumal of Clinical Nutrition, 34: 1526-1533.

41. Michaud C, Musse N, Nicolas J P \& Mejan L (1991). Effects of breakfast size on short-term memory concentration and blood glucose. J ournal of Adolescent Health, 12: 53-57.

42. Lloyd HM, Rogers PJ, Hedderley DI \& Walker AF (1996). Acute effects on mood and cognitive performance of breakfasts differing in fat and carbohydrate content. Appetite, 27: 151-164.

43. Spring B, Chiodo J \& Bowen DJ (1987).
Carbohydrates, tryptophan and behavior: a methodological review. Psychological Bulletin, 102: 234-256.

44. Spring B (1986). Effects of foods and nutrients on the behavior of normal individuals. In: Wurtman RJ \& Wurtman JJ (Editors), Nutrition and the Brain. Raven Press, New York, 1-47.

45. Sos J \& Szelenyi I (1974). Diets for animal experiments. Akademiai Kiado, 38-39.

46. Onaivi ES, Brock J W \& Prasad C (1992) Dietary protein levels alter rat behavior. Nutrition Research, 12: 1025-1039.

47. Brock J W, Ross K \& Prasad C (1998) Effects of high dietary protein on coping behavior, memory performance, and sensory discrimination in rats. Nutritional Neuroscience, 1: 305-314.

48. Asghar K (1987). Role of dietary and environmental factors in drug abuse. Alcohol and Drug Research, 7: 63-81.

49. Onaivi ES, Talton S \& Prasad C (1993). The level of protein in diet modulates the behavioral effects of amphetamine. In: Lehnert $H$, Murison $R$, Weiner $H$, Hellhammer D \& Beyer J (Editors), Endocrine and Nutritional Control of Basic Biological Functions. Hogrefer \& Huber Publishers, Toronto, 287-292.

50. Farooqui SM, BrockJ W, Onaivi ES, Hamdi A \& Prasad C (1994). Differential modulation of dopaminergic systems in the rat brain by dietary protein. Neurochemical Research, 19: 167-176.

51. Bartholini G, Stadler H, Gadea-Ciria M \& Lloyd KG (1977). Interaction of dopaminergic and cholinergic neurons in the extrapyramidal and limbic systems. In: Costa E \& Gessa GL (Editors), Advances in Biochemical Psychopharmacology. Raven Press, New York, 391-395.

52. German DC, Manaye K, Smith WK, Woodward DJ \& Saper CB (1989). Midbrain dopaminergic cell loss in Parkinson's disease: computer visualization. Annals of Neurology, 26: 507-514.

53. Le Moal M \& Simon H (1991). Mesocorticolimbic dopaminergic network: functional and regulatory roles. Physiological Reviews, 71: 155-234.

54. Munkvad I, Pakkenberg $\mathrm{H} \&$ Randrup $A$ (1968). Aminergic systems in basal ganglia associated with stereotyped hyperactive behavior and catalepsy. Brain Behavior and Evolution, 1: 89-100.

55. Niemegeers CJ E, M CGuire J L \& J anssen PAJ (1978). Domperidone, a novel gastrokinetic drug. Pharmacologist, 20: 209.

56. Carboni E, Imperato A, Perezzani L \& Di Chiara G (1989). Amphetamine, cocaine, phencyclidine, and nomifensine increase 
extracellular dopamine concentrations preferentially in the nucleus accumbens of freely moving rats. Neuroscience, 28 : 653-661.

57. Damsma G, Wenkstern D, Pfaus J G, Phillips AG \& Fibiger HC (1992). Sexual behavior increases dopamine transmission in the nucleus accumbens and striatum of male rats: comparison with novelty and locomotion. Behavioral Neurosci- ence, 106: 181-191.

58. Louilot A, Taghzouti K, Simon $\mathrm{H} \&$ Le Moal M (1989). Limbic system, basal ganglia, and dopaminergic neurons. Brain, Behavior and Evolution, 33: 157-161.

59. Weiss J M, Goodman PA, Losito BG, Corrigan S, Charry JM \& Bailey WH (1981). Behavioral depression produced by an uncontrollable stressor: relationship to norepinephrine, dopamine, and seroto- nin levels in various regions of rat brain. Brain Research Reviews, 3: 167-205.

60. White BD, Dean RG \& Martin RJ (1998). An association between low levels of dietary protein, elevated NPY gene expression in the basomedial hypothalamus and increased food intake. Nutritional Neuroscience, 1: 173-182. 


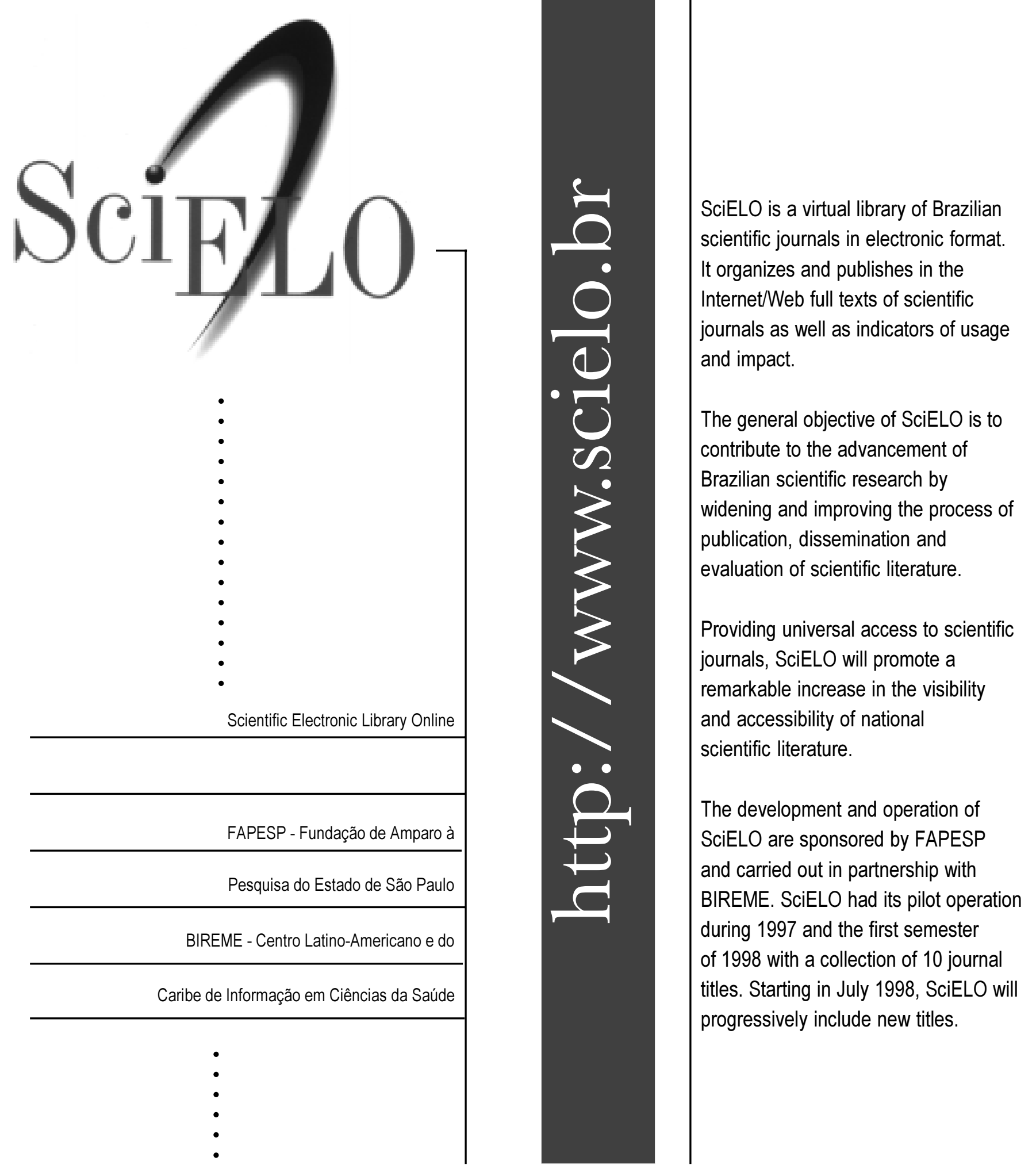

